\title{
Radioactive Deoxyglucose Uptake into the Heart Muscle of the Monkey
}

\author{
Ken'ichi Matsunami \\ Department of Neurophysiology, Primate Research Institute, \\ Kyoto University, Inuyama, Aichi, 484 Japan
}

\begin{abstract}
Summary The uptake of $\left[{ }^{14} \mathrm{C}\right]-2$-deoxy-D-glucose (2DG) into the heart muscle of the monkey was investigated. Increased 2DG uptake was observed in ventricular, trabecular and papillary muscles of the left ventricle. However, it was very small in the right ventricular and papillary muscles. The atrium or ascending arterial wall showed little 2DG uptake. Key Words: heart muscle, 2DG uptake, monkey.
\end{abstract}

Since the development of the $\left[{ }^{14} \mathrm{C}\right]$-2-deoxy-D-glucose (2DG) autoradiographic technique (SoKolofF et al., 1977), it has been applied to visualize increased neuronal activity in the central nervous system. The principle of this method consists in tracing glucose metabolism through the hexokinase-catalized phosphorylation step. Because the glucose metabolic pathway is not specific to the nervous structures, but very common to other tissues, this method seems applicable to other excitable cells. Therefore, we investigated whether or not the heart muscle incorporated 2DG. The heart muscle generates an automatic action potential with a plateau following a slowly depolarizing pacemaker potential in each beat cycle. As 2DG uptake depends largely on membrane depolarization and spike generation (SAJI and ОвATA, 1981), the autonomicity of the heart muscle provided us a unique opportunity to test $2 \mathrm{DG}$ uptake without any additional experimental operation such as electrical stimulation of the muscle.

Four monkeys (1 Macaca mulatta, 3 Macaca fuscatas) were used. Two monkeys voluntarily performed intensive extension-flexion movements at the wrist joint. Another two performed moderate extension-flexion movements. The difference between the two movements did not seem to affect the qualitative result regarding $2 \mathrm{DG}$ uptake into the heart muscle. A few days before injection of 2DG, a cannula (CUTTER Resiflex, 5 Fr., Cutter Laboratories Pacific) was chronically implanted in the internal jugular vein. On the day of the experiment, the monkey was administered with $2 \mathrm{DG}(100 \mu \mathrm{Ci} / \mathrm{kg})$ through the implanted cannula. The monkey was then allowed to continue the extension-flexion move-

Received for publication September 14, 1981

松波謙一 
ment for $45 \mathrm{~min}$, after which time it was anesthetized with sodium pentobarbital $(50 \mathrm{mg} / \mathrm{kg}$, i.v.) and was killed by injection of $\mathrm{KCl}$ solution through the cannula. After death, the heart was removed, frozen in the freezing bath of a cryostat $\left(-45^{\circ} \mathrm{C}\right)$, and stored in a freezer $\left(-20^{\circ} \mathrm{C}\right)$. A section was cut of $30 \mu \mathrm{m}$ thickness in the cryostat (Cryostato-microtome, CR-520, Yamato Koki) at $-20^{\circ} \mathrm{C}$, dried under the warm blast of a hair dryer and then on a heat plate $\left(60^{\circ} \mathrm{C}\right)$. The sections were then stored in a cassette, and covered with an X-ray film (KX, Fuji) for 3-5 days development of the film took $5 \mathrm{~min}$ (Rendol, Fuji).

Figure 1 shows autoradiographs of the heart muscle of a monkey. Sections were chosen from three different levels of the longitudinal axis of the heart. The 2DG uptake was greater in the left than in the right ventricular muscle throughout the whole heart (Figs. 1A-C). In Fig. 1A, intensive 2DG uptake was observed along the intraventricular septal wall. Increased 2DG uptake was also observed in the left ventricular wall, with the epicardial side more intensively labelled. Trabeculae carneae of the left ventricle appear in Fig. 1A with as much or less 2DG uptake as observed in the ventricular wall. Trabeculae carneae appear also in the right ventricle, but the amount of 2DG uptake was small. Figure $1 \mathrm{~B}$ shows a section at the broadest part of the heart. The left ventricular muscle appears in annulus and the right ventricle in crescent. 2DG was concentrated in the left ventricular wall, and was significant in the intraventricular septum and in the left half of the left ventricular wall. At this level of longitudinal axis, left ventricular papillary muscles $\left(\mathrm{P}_{1}, \mathrm{P}_{2}, \mathrm{P}_{3}\right)$ are recognized, incorporating as much $2 \mathrm{DG}$ as the left ventricular wall. But $2 \mathrm{DG}$ uptake into the right ventricular muscle was low, especially in the middle part of the free wall. Microscopic examination revealed that this part of the right ventricular wall had sparse muscular structures. Papillary muscles $\left(\mathrm{p}_{1}, \mathrm{p}_{2}, \mathrm{p}_{3}\right)$ and some trabeculae are also observed in the right ventricle. 2DG uptake into both structures was low compared to the corresponding structures of the left ventricle.

Figure $1 \mathrm{C}$ shows the heart near the basis. The amount of $2 \mathrm{DG}$ uptake in the left ventricular wall was large, but it was small in the right ventricular wall. In this figure, a part of the atrium and the ascending aorta are illustrated, 2DG uptake into both structures being very small.

The present study showed the increased 2DG uptake into the heart muscle. This is consistent with the fact that $2 \mathrm{DG}$ uptake depends on spike generation and membrane depolarization (SAJI and OBATA, 1981). The distinct 2DG uptake in the present experiment suggested that glucose was one of the better substrates for the energy source of the heart muscle in the physiological state, though free

Fig. 1. Incorporation of radioactive 2-deoxyglucose into heart muscle. A, B, C: three sections from different levels of the longitudinal axis of the heart. A, a section near the apex; $\mathrm{B}$, a section at the middle of the heart; $\mathrm{C}$, a section near the basis. Darkened areas show increased incorporation of deoxyglucose. $\mathrm{P}_{1}, \mathrm{P}_{2}, \mathrm{P}_{3}$ : papillary muscles in the left ventricle. $p_{1}, p_{2}, p_{3}$ : papillary muscles in the right ventricle. a: the ascending aorta. 


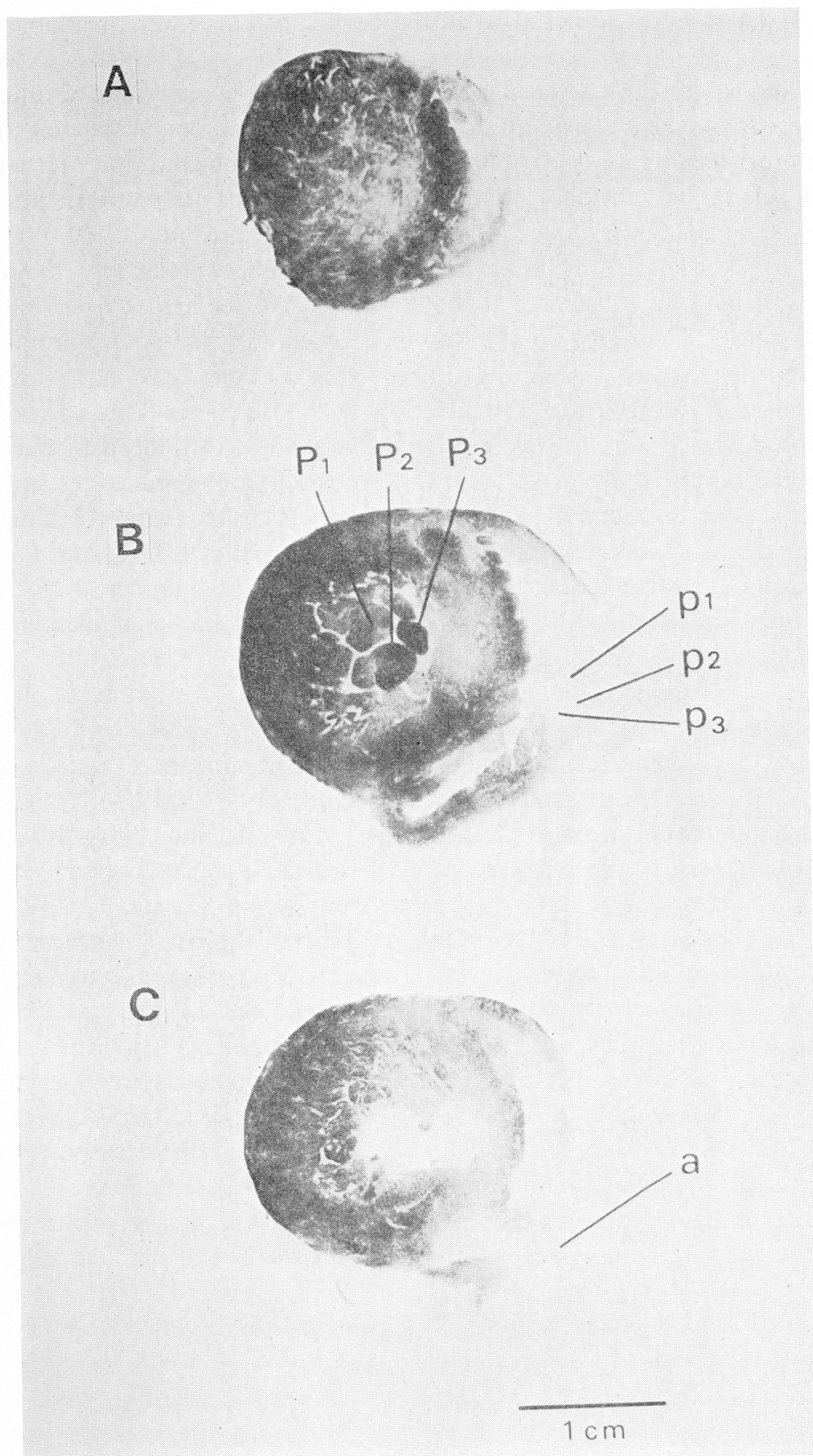

Fig. 1.

Vol. 32, No. 2, 1982 
fatty acid was more preferential when the both substances were available (GIBBS, 1978).

The increased 2DG uptake into the heart muscle may also be interpreted in relation to oxygen consumption in this muscle. Previous studies reported that there existed high correlations between oxygen consumption and some parameters related to tension in the heart muscle (BRITMAN and LEVINE, 1964; MCDonald et al., 1966; SARnoff et al., 1958; SugA et al., 1980; Weber and JANICKI, 1977). Therefore, the large amount of 2DG uptake into the left ventricular wall may be considered to be correlated with a high tension developed in this muscle. The $2 \mathrm{DG}$ uptake was more significant in the epicardial side of the left ventricular wall. This would imply that a higher tension was developed in the epicardial side of the left ventricular wall. But from the measurement of sarcomere length, it was suggested that the inner wall produced higher tension than did the outer (YoRAN et al., 1973). However, the length difference of sarcomeres between the outer and the inner ventricular muscle was not detectable on measurement in the diastolic stage after death (LinzBACH and LinzBACH, 1951). Consequently, we would like to speculate from the manner of 2DG uptake into the heart muscle that the ventricular muscle developed its maximam tension in the middle to epicardial side of the ventricular wall.

As 2DG uptake depends on spike generation and membrane depolarization (SAJI and OватA, 1981), the regional difference of 2DG uptake in the heart may alternatively be considered as a reflection of the different duration of spikes and plateaux in different heart structures. The duration of a spike or a plateaux is longer in the outer epicardial wall, inner epicardial wall, atrium and arterial wall, in that order (HofFMAN and CRANEFIELD, 1960).

Another important point in the present study is that the left ventricular papillary muscles showed as much $2 \mathrm{DG}$ uptake as did the left ventricular wall. So far as we adopt the same reasoning for the relation of $2 \mathrm{DG}$ uptake to tension development as in the ventricular wall, it may be concluded that the papillary muscles in the left ventricle produced as much tension as in the left ventricular wall. But when examined carefully, the manner of $2 \mathrm{DG}$ uptake differed among papillary muscles. Some papillary muscle $\left(\mathrm{P}_{1}\right.$, for example) accumulated $2 \mathrm{DG}$ less than another $\left(\mathrm{P}_{3}\right.$, for example). This is probably because the fractions of tension assigned to each papillary muscle during a systolic period differed, as the mechanical properties of the respective valves and the numbers of other papillary muscles attached to them would be different (ANDERSON and BECKER, 1980).

The author expresses his thanks to Mrs. Takako Miwa for preparation of photographs.

\section{REFERENCES}

Anderson, R. H. and Becker, A. E. (1980) Cardiac Anatomy, Gower Medical Publ., London. Britman, N. A. and Levine, H. J. (1964) Contractile element work: A major determinant of 
myocardial oxygen consumption. J. Clin. Invest., 43: 1397-1408.

GibBs, C. L. (1978) Cardiac energetics. Physiol. Rev., 58: 174-254.

Hoffman, B. R. and CRANefield, P. F. (1960) Electrophysiology of the Heart. McGrawHill, London and New York.

Linzbach, A. J. and Linzbach, M. (1951) Die Herzdilatation. Klin. Wochenschr., Jahrgang, 29: $621-630$.

McDonald, R. H., TAYlor, R. R., and Cingolani, H. E. (1966) Measurement of myocardial developed tension and its relation to oxygen consumption. Am. J. Physiol., 211: 667-673.

SAJI, M. and ОватA, K. (1981) Stimulus-dependent labeling of cultured ganglionic cell with $\left[{ }^{14} \mathrm{C}\right]$ 2-deoxyglucose. Brain Res., 212: 435-446.

Sarnoff, S. J., Braunwald, E., Welch, G. H., Case, R. B., Stainsby, W. N., and Marcruz, R. (1958) Hemodynamic determinants of oxygen consumption of the heart with special reference to the tension-time index. Am. J. Physiol., 192: 148-156.

Sokoloff, L., Reivich, M., Kennedy, C., Des Rosiers, M. H., Patlak, C. S., Pettigrew, K. D., Sakurada, O., and Shinohara, M. (1977) The $\left[{ }^{14} \mathrm{C}\right]$ deoxyglucose method for the measurement of local cerebral glucose utilization: Theory, procedure, and normal values in the conscious and anesthetized albino rat. J. Neurochem., 28: 897-916.

Suga, H., Hayashi, T., and Shimamura, M. (1980) Critical evaluation of left ventricular systolic pressure volume area as predictor of oxygen consumption rate. Jpn. J. Physiol., 30: 907-919.

WeBER, K. T. and JANICKI, J. S. (1977) Myocardial oxygen consumption: The role of wall force and shortening. Am. J. Physiol., 233: H421-H430.

Yoran, C., Covell, J. W., and Ross, J. Jr. (1973) Structural basis of the ascending limb of left ventricular function. Circ. Res., 32: 297-303. 